\title{
Closure of a nonhealing gastrocutaneous fistula using argon plasma coagulation and endoscopic hemoclips
}

\author{
H Hameed MBBS, MRCP, S Kalim MBBS, YI Khan MBBS MD
}

H Hameed, S Kalim, YI Khan. Closure of a nonhealing gastrocutaneous fistula using argon plasma coagulation and endoscopic hemoclips. Can J Gastrenterol 2009;23(3):217-219.

A case in which a gastrocutaneous fistula developed after percutaneous endoscopic gastrostomy tube placement is presented. The fistula was first managed conservatively, then was closed by argon plasma coagulation and hemoclip placement. The patient was observed and was discharged once the gastrocutaneous fistula closed.

Key Words: Argon plasma coagulation; Gastrocutaneous fistula; Hemoclips; Percutaneous enteral gastrostomy

\section{La fermeture d'une fistule gastrocutanée réfractaire par photocoagulation au laser argon et installation de pinces endoscopiques}

\begin{abstract}
Les auteurs présentent un cas de fistule gastrocutanée qui s'est formée après l'installation d'une sonde de gastrostomie endoscopique percutanée. On a d'abord adopté un traitement classique de la fistule, qu'on a ensuite fermée par photocoagulation au laser argon et installation de pinces endoscopiques. Le patient, maintenu en observation, a obtenu son congé une fois la fistule fermée.
\end{abstract}

T he use of percutaneous endoscopic gastrostomy (PEG) has been increasing, and has become a safe and effective technique for enteral feeding. Persistent gastrocutaneous fistula (GCF) after gastrostomy tube removal is a well-recognized sequela of long-term use, with a reported incidence of $2 \%$ to $44 \%$. Conservative therapy with $\mathrm{H}_{2}$ blockers and promotility agents, as well as mechanical plugging of the fistula with topical skin adhesives such as cyanoacrylate, has had mixed success. For this reason, persistent GCFs usually require surgical correction.

\section{CASE PRESENTATION}

A 65-year-old man with T3NOMO squamous cell carcinoma of the right alveolus with buccal mucosal involvement was referred for PEG tube placement before chemoradiation of the tumour. A PEG tube was placed on October 15, 2007 and the procedure was uneventful. The patient was scheduled for concurrent chemoradiation, but had received only seven cycles of radiotherapy when he presented to the emergency department with complaints of peri-PEG leakage on March 10, 2008. On clinical examination, there were local peri-PEG indurations along with hemorrhagic discharge but no signs of peritonitis. The patient was admitted and put on conservative management, and the PEG tube was removed on March 11, 2008. The patient was discharged on March 12, 2008 but he again presented to the emergency room with complaints of leakage of food from the epigastric PEG tube removal site. He was admitted with a diagnosis of persistent GCF (Figure 1). He was kept nil per os along with antibiotics and parenteral nutrition. Discharge from the PEG removal site did not settle and the fistula did not close on its own. Consequently, endoscopic closure was planned. First, argon plasma coagulation (APC) was used to denude the lining of the fistulous tract (Figure 2). Then, four endoclips were applied to approximate the adjacent mucosal wall (Figures 3 and 4), thus mechanically closing the fistula. A decrease in discharge was noted from the next day onward. The fistula dried up on the second day and the patient was started on liquids on day 3 . The patient was discharged four days after endoscopic closure of the GCF.

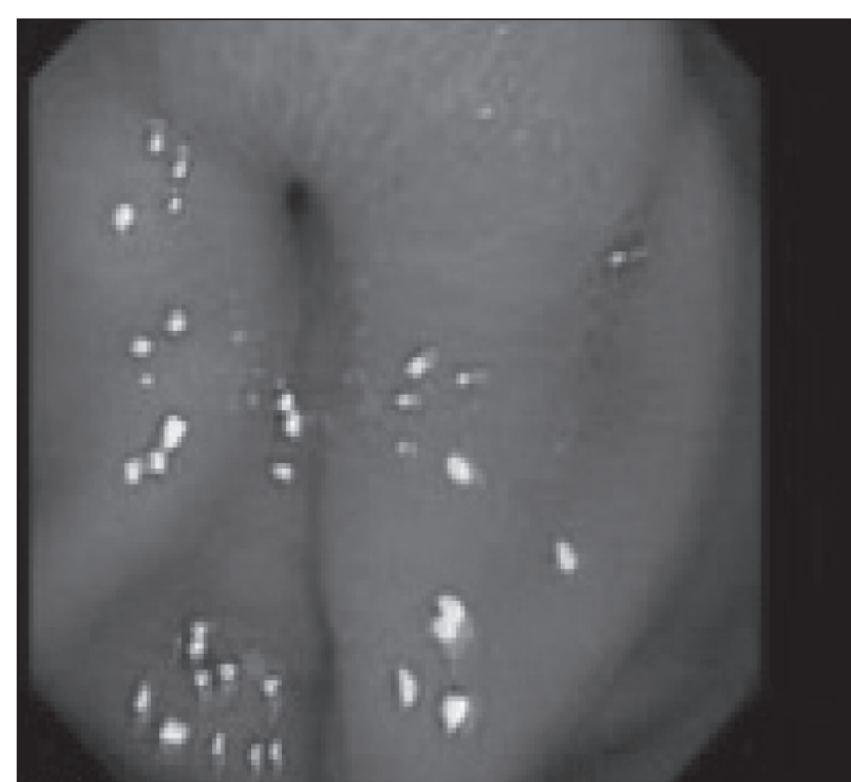

Figure 1) Opening of gastrocutaneous fistula seen at gastrostomy site

\section{DISCUSSION}

PEG tubes are used to provide long-term enteral nutrition and prophylactically in patients scheduled for radiation to the head and neck area, which usually causes mucositis and dysphagia. Although the communication between the stomach and skin usually closes within a few hours to days after gastrostomy tube removal, a rare complication of persistent GCF may develop in $2 \%$ to $44 \%$ of patients (1). A persistent GCF has been defined as the persistence of the gastrostomy tract one month after removal of the gastrostomy tube. This is more common when the gastrostomy tube has been in place for more than nine to 11 months (2). Different treatment modalities have been attempted, including conservative medical and surgical correction of GCF. The aim of conservative medical therapy is to

Department of Medicine, Shaukat khanum Memorial Cancer Hospital and Research Centre, Lahore, Pakistan

Correspondence and reprints: Dr H Hameed, Shaukat khanum Memorial Cancer Hospital and Research Centre, Johar Town, Lahore 51850,

Punjab, Pakistan. Telephone 92-321-4643052, fax 92-42-5945120, e-mail hameed142@gmail.com

Received for publication June 9, 2008. Accepted June 20, 2008 


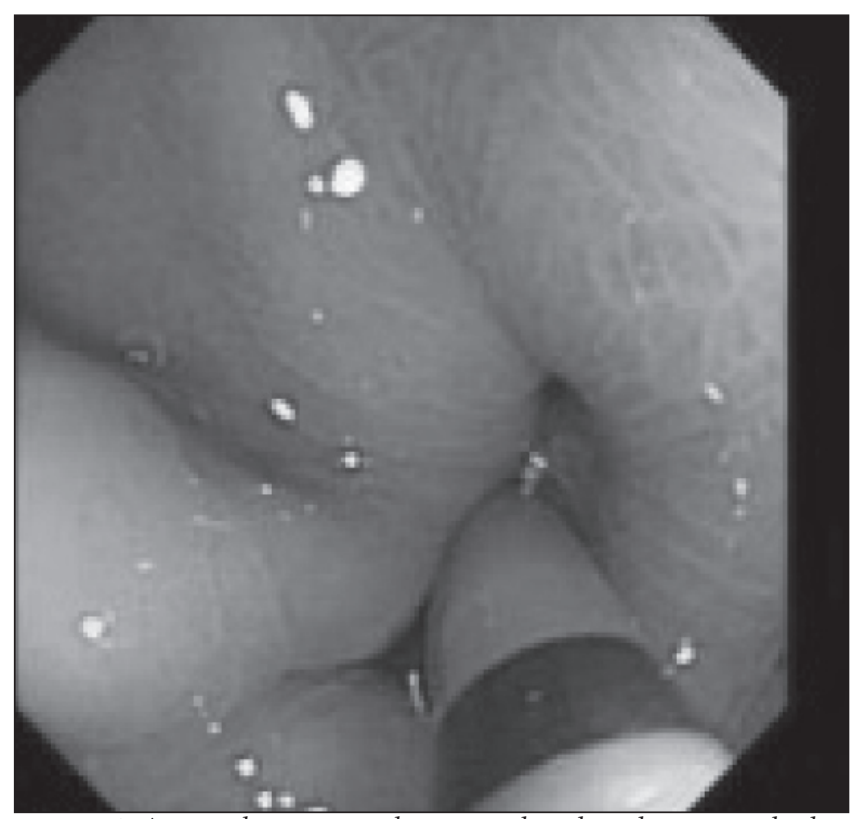

Figure 2) Argon plasma coagulation used to denude tract and adjacent mucosa

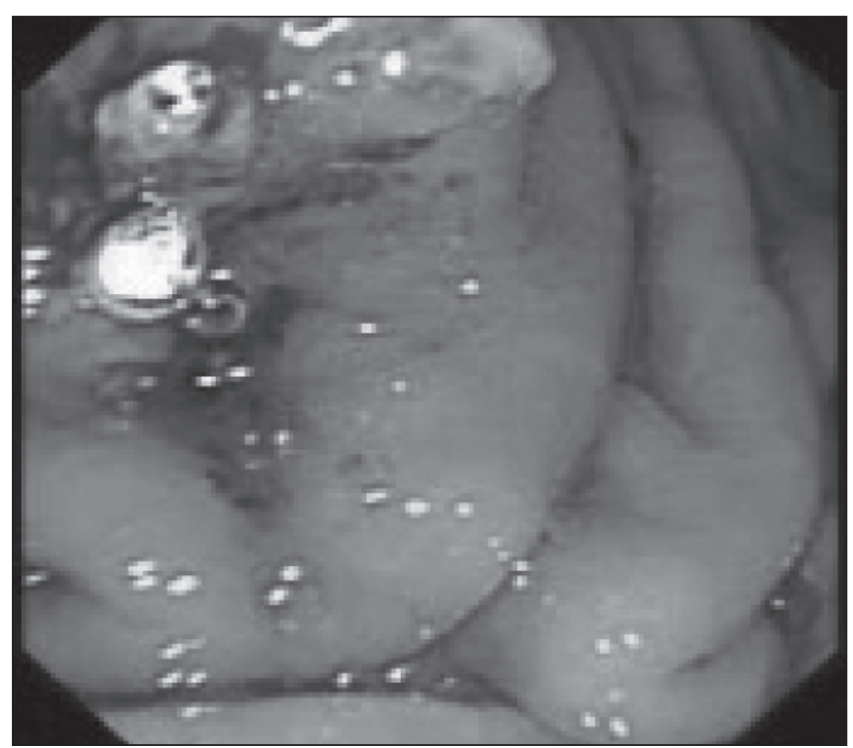

Figure 3) Superficial mucosal ulcers after application of argon plasma coagulation

increase gastric emptying, increase gastric $\mathrm{pH}$ and decrease intragastric pressure $(3,4)$. Kobak et al (3) achieved fistula closure in $53 \%$ of cases by cauterization with silver nitrate and an $\mathrm{H}_{2}$ antagonist (3). Others have described the application of collagen plugs, with mixed results $(5,6)$. Several published case series have described the use of cyanoacrylate glue for closure of intractable enterocutaneous fistulas; however, this approach has not been critically evaluated or widely adopted $(7,8)$. Usually, surgical correction is reserved for GCFs intractable to other modalities $(9,10)$.

Application of an endoclip as a therapeutic endoscopic manoeuvre was described by Hayashi et al (11) in Japan more than 22 years ago. It is now in use for various clinical situations including the treatment of gastrointestinal bleeding, as well as

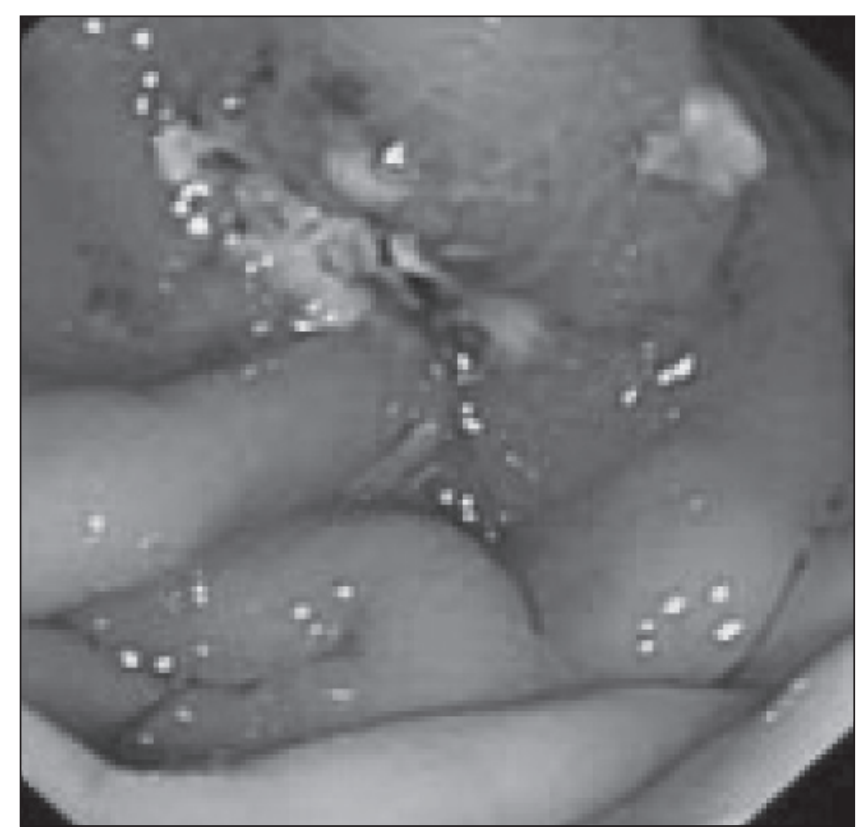

Figure 4) Edges of mucosal wall approximated with hemoclips

the intraluminal closure of tissue defects, perforations and anastomotic leaks. There have been only a few previously reported cases of closure of a nonhealing GCF using endoscopic clips $(12,13)$. Different combinations of modalities, such as endoclip with cyanoacrylate and endoclip with cautery have been reported in the literature for the management of GCFs $(14,15)$. There is a small risk of endoscope damage with cyanoacrylate injection and its availability may also be an issue in certain centres.

In the present report, endoclips were applied with a clip applicator device. For the closure of the fistula tract, APC was first used to coagulate the area and then an endoclip was used to grasp the margins of the defect and approximate the tissue. This procedure was found to be effective and the patient improved within days of closure of the fistula. The combination of APC with the implantation of endoclips for closure of GCFs opens a new modality for the management of GCFs.

\section{CONCLUSION}

Our experience shows that the placement of endoclips, along with APC, may prove useful in patients with refractory GCFs, and should be considered as a first-line therapy in refractory cases and preclude the use of surgery for the closure of a GCF.

\section{REFERENCES}

1. Mahajan L, Oliva L, Wyllie R, et al. The safety of gastrostomy in patients with Crohn's disease. Am J Gastroenterol 1997;92:985-8.

2. Gordon JM, Langer JC. Gastrocutaneous fistula in children after removal of gastrostomy tube: Incidence and predictive factors. J Pediatr Surg 1999;34:1345-6.

3. Kobak GE, McClenathan DT, Schurman SJ. Complications of removing percutaneous endoscopic gastrostomy tubes in children. J Pediatr Gastroenterol Nutr 2000;30:404-7.

4. Deruyter L, Van Blerk M, Cadiere GB, et al. Treatment of highoutput gastric fistulas with omeprazole. Hepatogastroenterology 1991;38:83-6.

5. Lomis NN, Miller FJ, Loftus TJ, et al. Refractory abdominalcutaneous fistulas or leaks: Percutaneous management with a collagen plug. J Am Coll Surg 2000;190:588-92. 
6. Gonzalez-Ojeda A, Avalos-Gonzalez J, Mucino-Hernandez MI, et al. Fibrin glue as adjuvant treatment for gastrocutaneous fistula after gastrostomy tube removal. Endoscopy 2004;36:337-41.

7. Lee YC, Na HG, Suh JH, Park IS, Chung KY, Kim NK. Three cases of fistulae arising from gastrointestinal tract treated with endoscopic injection of Histoacryl. Endoscopy 2001;33:184-6.

8. Gdanietz K, Krause I. Plastic adhesives for closing esophagotracheal fistulae in children. Z Kinderchir 1975;17:137-8.

9. Pearlstein L, Jones CE, Polk HC Jr. Gastrocutaneous fistula: Etiology and treatment. Ann Surg 1978;187:223-6.

10. Bender JS, Levison MA. Complications after percutaneous endoscopic gastrostomy removal. Surg Laparosc Endosc 1991;1:101-3.
11. Hayashi T, Yonezawa M, Kawabara T. The study on staunch clip for the treatment by endoscopy. Gastroenterol Endosc 1975;17:92-101.

12. Thurairajah P, Hawthorne AB. Endoscopic clipping of a nonhealing gastrocutaneous fistula following gastrostomy removal. Endoscopy 2004:36:834

13. Siddiqui AA, Kowalski T, Cohen S. Closure of nonhealing gastrocutanous fistula using an endoscopic clip. South Med J 2007;100:75-6.

14. Teitelbaum JE, Gorcey SA, Fox VL. Combined endoscopic cautery and clip closure of chronic gastrocutaneous fistula. Gastrointest Endosc 2005;62:432-5

15. Alberti J, Alberti-Flor JJ. Endoclip-assisted closure of infected gastrocutaneous fistulas. Endoscopy 2005;37:403. 


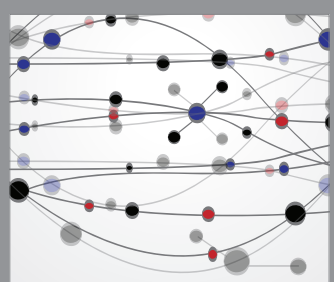

The Scientific World Journal
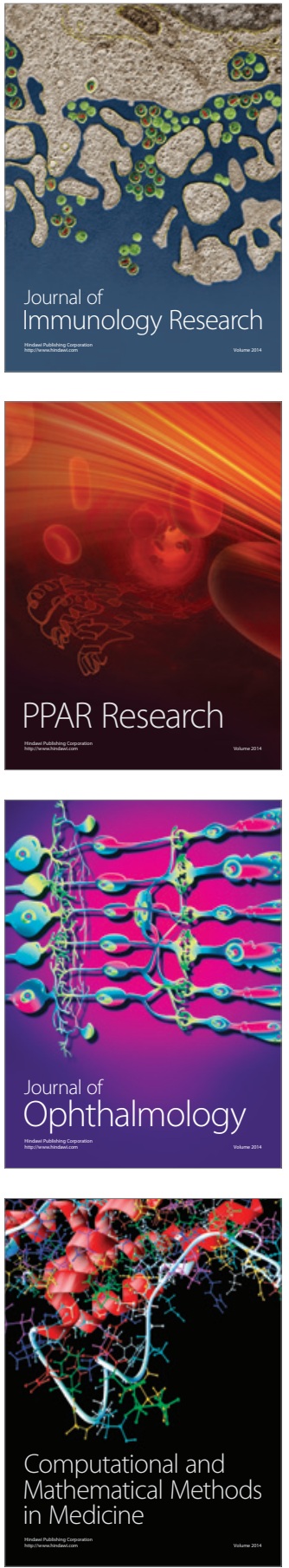

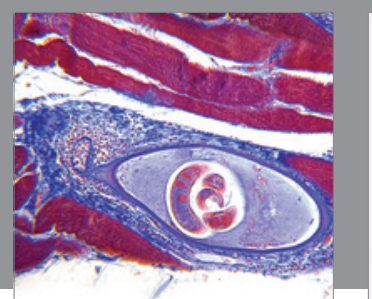

Gastroenterology Research and Practice

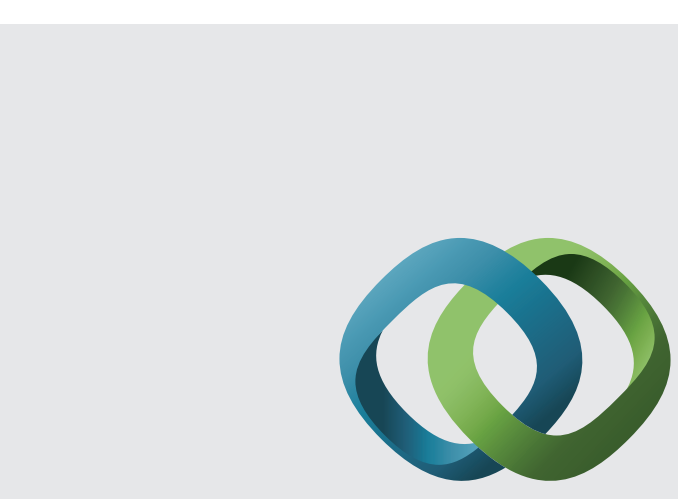

\section{Hindawi}

Submit your manuscripts at

http://www.hindawi.com
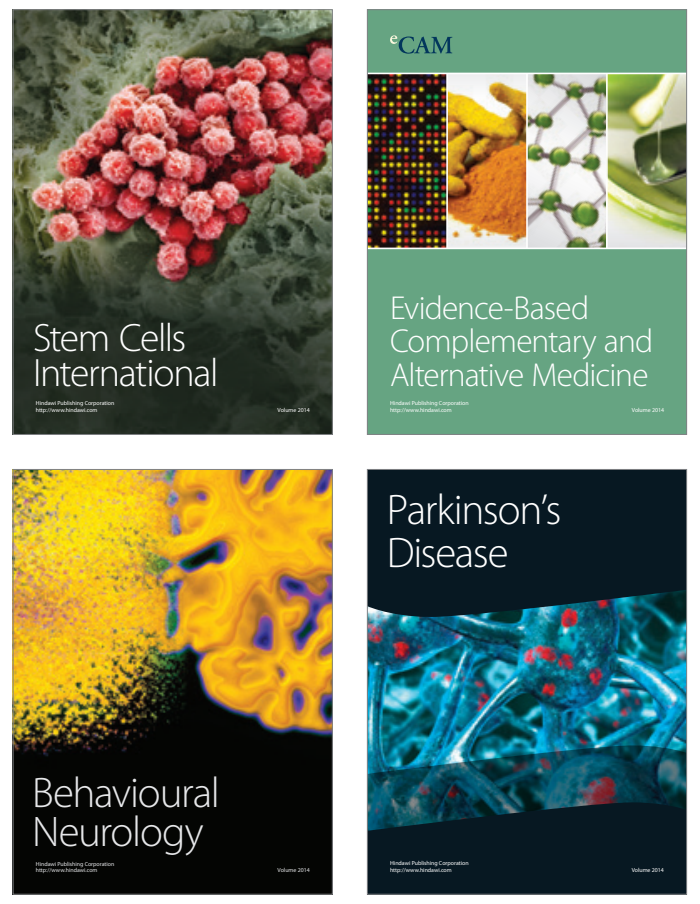
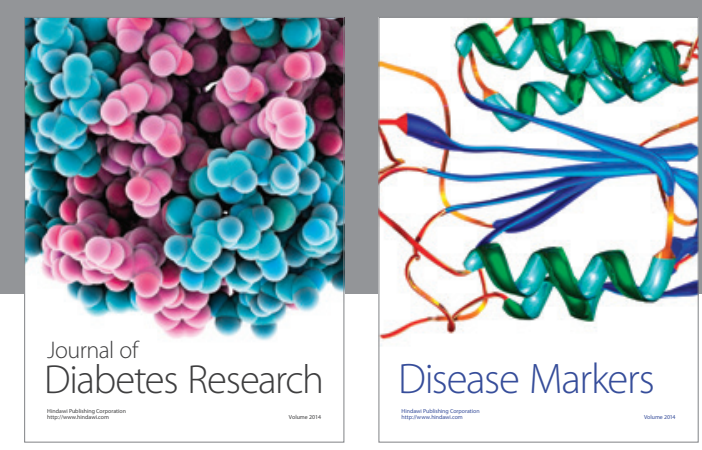

Disease Markers
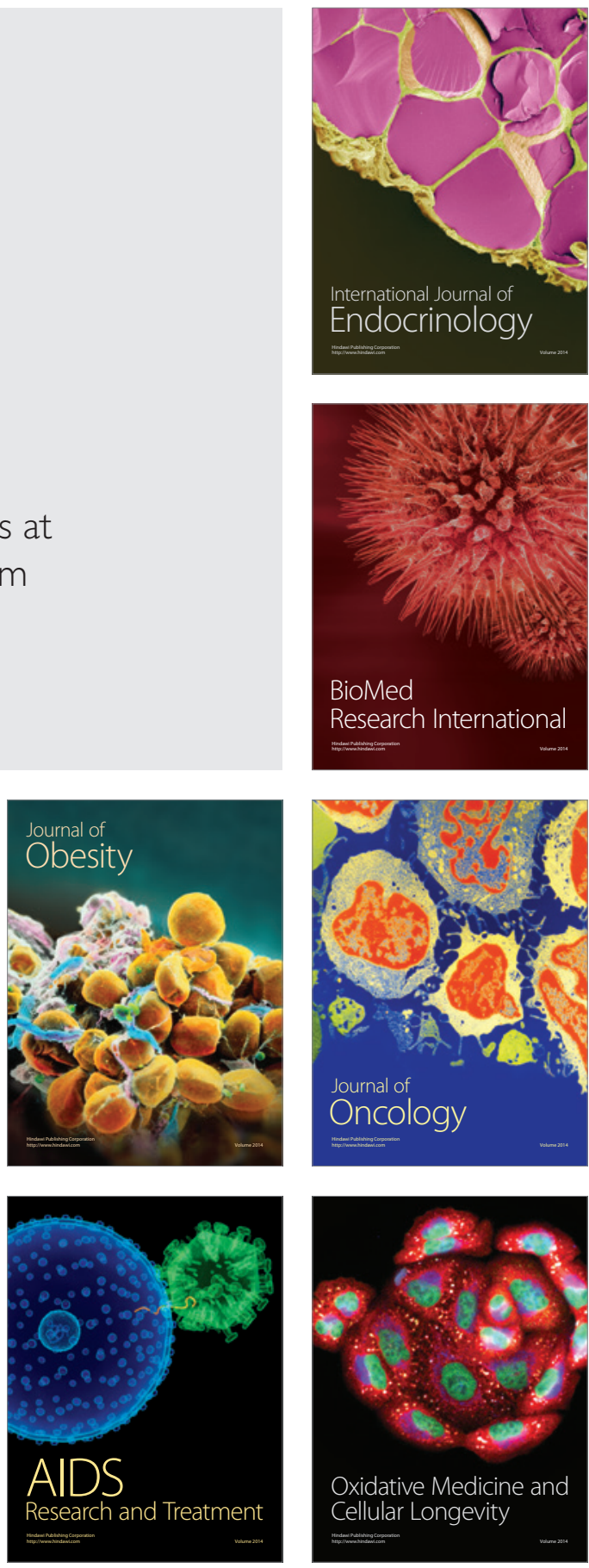